Communications in Physics, Vol.20, No. 4 (2010), pp. 365-369

\title{
THE SYNTHESIS AND PHOTOLUMINESCENCE OF 3C-SiC NANORODS
}

\author{
HUYNH THI HA, DAO TRAN CAO, LE QUANG HUY, \\ AND NGUYEN THE QUYNH \\ Institute of Materials Science, VAST
}

\begin{abstract}
The 3C-SiC nanorods were grown by using carbothermal reduction of $\mathrm{SiO}_{2}$ without any catalyst. The intensive broad photoluminescence peak around 480-500 $\mathrm{nm}$ was observed at room temperature. The 3C-SiC nanorods with green - blue emitting light may have great application in display devices and light emitting diodes.
\end{abstract}

\section{INTRODUCTION}

Silicon carbide $\mathrm{SiC}$ is one of the wide-band gap semiconductors with many superior characteristics, which make great applications in high speed, high temperature and highpower devices in harsh environments. However, due to its indirect band gap, bulk $\mathrm{SiC}$ is not considered as a promising material for light emitting devices. Since the strong visible photoluminescence from porous silicon at room temperature was discovered [1], intensive light emitting from low-dimension indirect-band gap semiconductors became attractive research. There were several studies on photoluminescence (PL) of porous and thin film $\mathrm{SiC}$ prepared by different techniques $[2,3]$. There are also some studies on $\mathrm{PL}$ of $\mathrm{SiC}$ nanowires synthesized by chemical vapor deposition method or by using catalyst $[4,5,6]$. But the PL properties of SiC nanorods produced by carbothermal reduction, which have individual shell-core structure are unknown.

In this work, we investigate the PL of $\mathrm{SiC}$ nanorods synthesized by carbothermal reduction. Our samples are grown from silica xerogel containing carbon nanoparticles. The morphology and structure of the product are determined by using transmision electronmicro spectrometer and X-ray diffraction. An intensive blue-green light emission at 480 $\mathrm{nm}$ is observed at room temperature. The luminescence origin and potential applications are discussed.

\section{EXPERIMENTAL}

Our samples of $\mathrm{SiC}$ nanorods were prepared in high temperature vacuum furnace. Commercial precursor tetraethoxysilane $\mathrm{Si}\left(\mathrm{OC}_{2} \mathrm{H}_{5}\right)_{4}$ and saccharrose $\mathrm{C}_{12} \mathrm{H}_{22} \mathrm{O}_{11}$ were mixed and then dried by the same method presented in previous report [8]. The performed silica xerogel containing carbon nanoparticles was placed in graphite boat which put at center of the furnace. The boat was gradually heated up and kept at $1550{ }^{0} \mathrm{C}$ for 3 hours under flowing argon. The treated SiC powder was taken out when it was cooled down to room temperature. 
The as-grown products were characterized with transmission electron microscope (JEM1010 JEOL), X-ray diffraction (XRD D8 ADVANCE Bruker), micro-Raman spectroscopy (LABRAM-1B Jobin Yvon). PL measurements were performed at room temperature using He-Cd laser for ultraviolet excitation light $\lambda=325 \mathrm{~nm}$ (Microspec 2300i). The laser beam was focused into a spot with diameter of about $0.1 \mathrm{~mm}$ on the sample.

\section{RESULTS AND DISCUSSION}

Silicon carbide nanorods were synthesized by carbothermal reduction of $\mathrm{SiO}_{2}$ without any catalyst assistance. The nucleation in small size of nanorods was carried out on base of fine grinding silica xerogel containing carbon nanoparticles. The growth of $\mathrm{SiC}$ nanorods is dominated by the vapor-liquid-solid progress. The solid $\mathrm{SiO}_{2}$ was converted from liquid to vapor state after $1200{ }^{0} \mathrm{C}$ and reacted with $\mathrm{C}$ in solid state; then $\mathrm{SiC}$ nucleation performed. The growth was processed at temperature $1550^{\circ} \mathrm{C}$.

Figure 1a shows a general overview of the TEM images of above mentioned synthesized product. The morphology seems to be polytype straight curved rod-like structures with outside diameter of about $20-40 \mathrm{~nm}$.

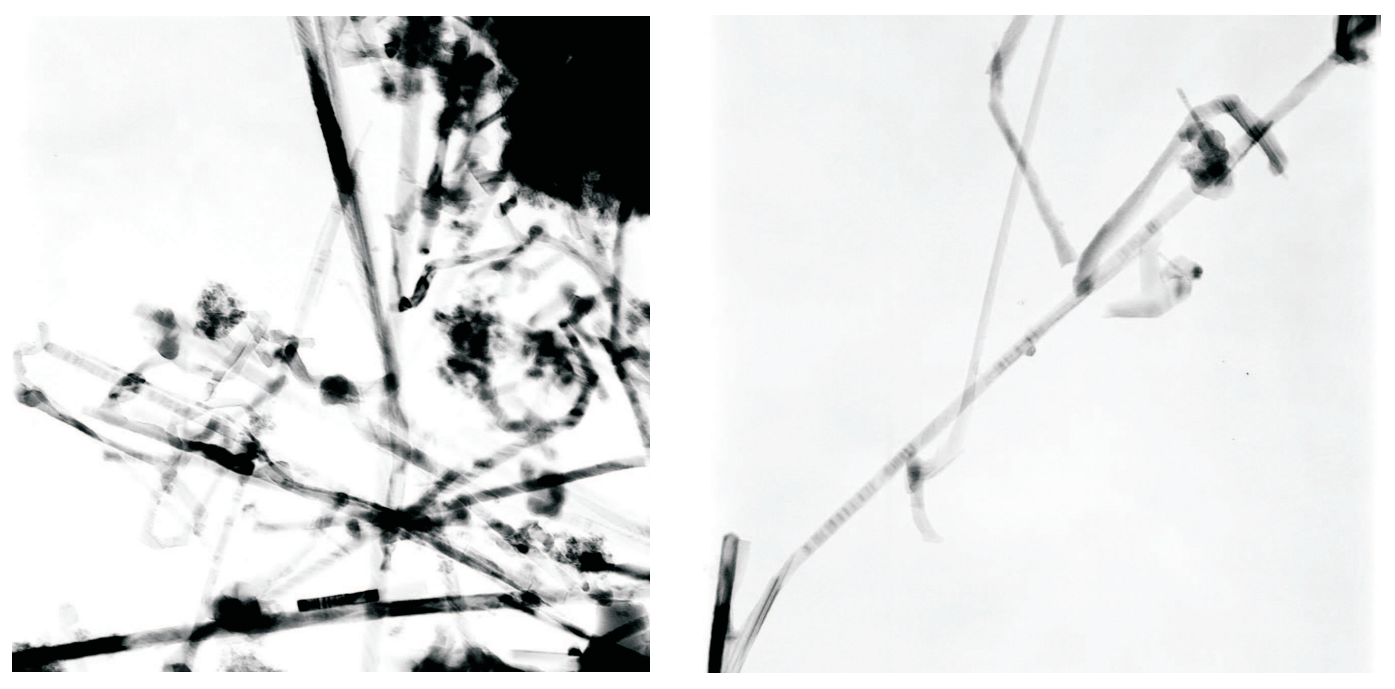

Fig. 1. TEM images of synthesized $\mathrm{SiC}$ by carbothermal reduction of silica

Figure 2 demonstrates structure measurement of synthesized product. The XRD pattern shows typical lines of $3 \mathrm{C}-\mathrm{SiC}$ structure. The amorphous $\mathrm{SiO}_{2}$ at about 20 degrees of 2-Theta angle is also presented. In the same growth technique, Meng and coauthors had indicates that when anneal proceeded at temperature below $1600^{\circ} \mathrm{C}$, the synthesized nanorods consisted of crystalline $\mathrm{SiC}$ core and amorphous $\mathrm{SiO}_{2}$ shell [7]. Therefore, we suggest that our synthesized product has the structure of crystalline 3C-SiC core wrapped with amorphous $\mathrm{SiO}_{2}$ shell.

Results of Raman scattering measurement confirms a diminution of $\mathrm{SiC}$ wire size to nanometer range. The Raman spectrum of synthesized material is shown in Fig. 3. 


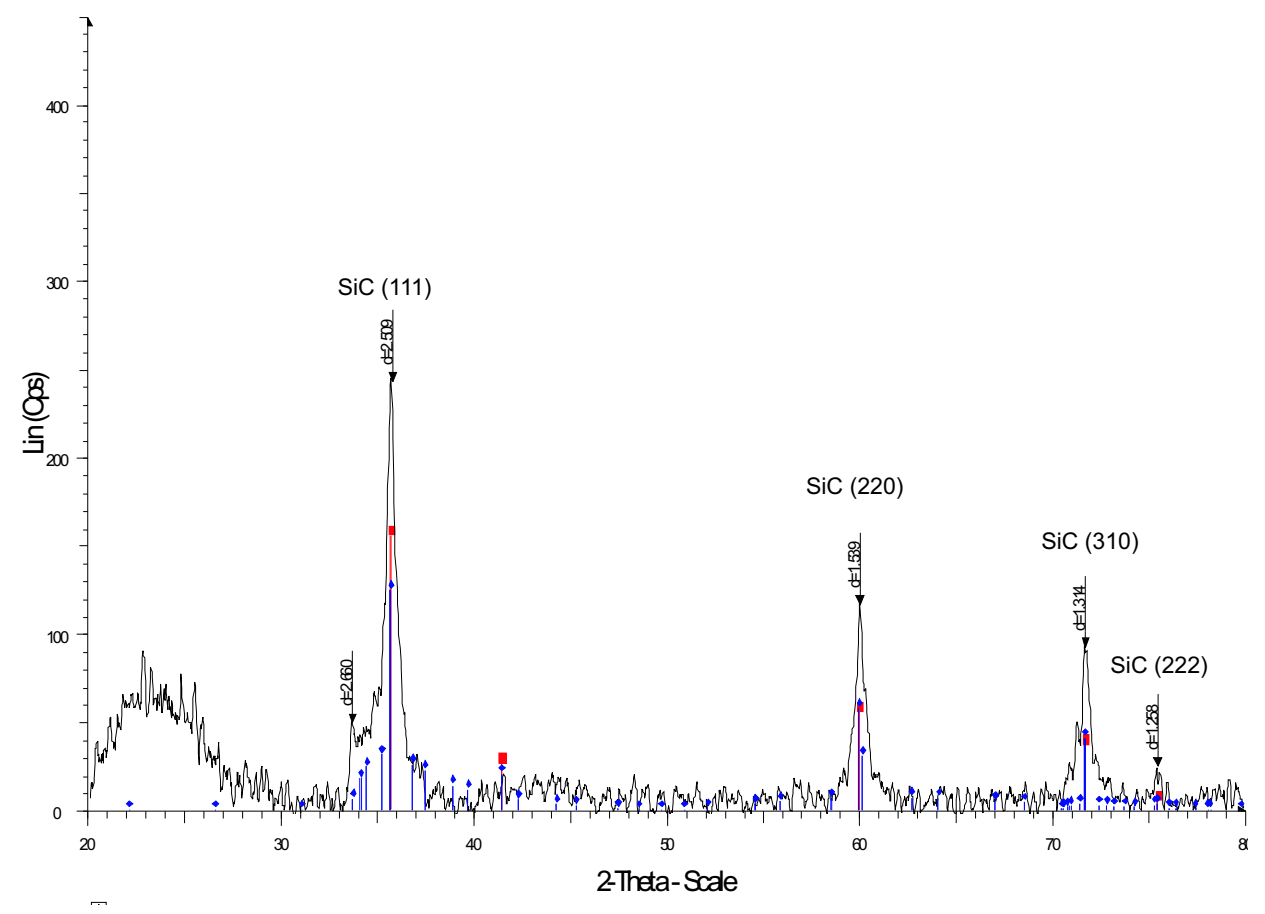

Fig. 2. XRD measurements of synthesized $\mathrm{SiC}$ material.

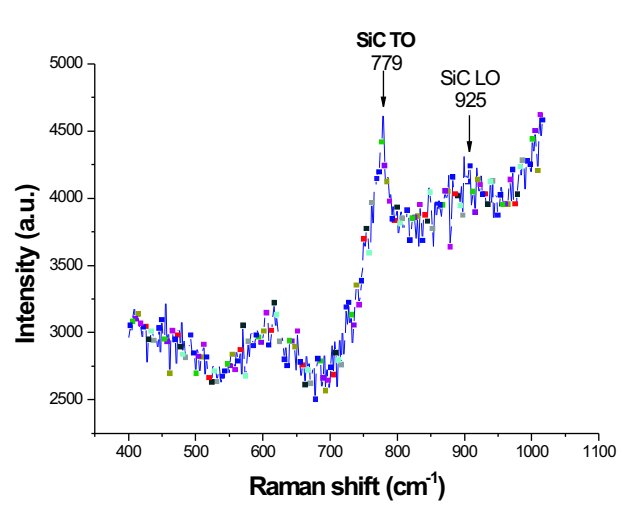

(a)

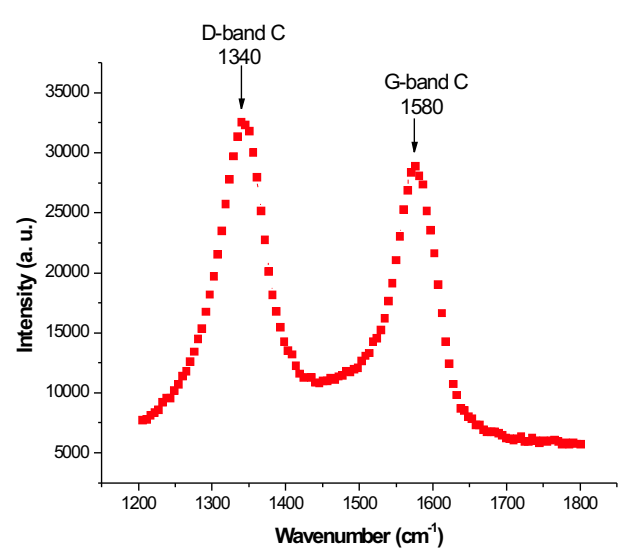

(b)

Fig. 3. Raman scattering measurement of as-grown $\mathrm{SiC}$ material.

Compared with bulk SiC, where phonon TO and LO modes have been at 790 and 965 $\mathrm{cm}^{-1}$ respectively[8], it is clear that there is red-shift of phonon TO and LO modes of our synthesized $\mathrm{SiC}$ (779 and $925 \mathrm{~cm}^{-1}$ respectively, in Fig. 3a). It is reasonable to interpret 
this shift with a microcrystal model based on the size confinement effect and internal stress within $\mathrm{SiC}$ core when the temperature of furnace lowered to room temperature after preparation. Fig. 3b shows also carbon existence of as-grown product through some typical Raman scattering peaks. They are clearly Raman signals as G-band at $1580 \mathrm{~cm}^{-1}$ and D-band at $\sim 1340 \mathrm{~cm}^{-1}$. It seems belong to remaining excess carbon in reaction of forming $\mathrm{SiC}$ nanorods.

Because of intense absorption of excess carbon, the PL of as-grown SiC material could not be defined at room temperature. In order to eliminate excess carbon before PL measurement, the material was annealed in ambient air at different temperatures for one hour. Fig. 4 shows PL spectra of the same synthesized material annealed at 800, 900 and $1000^{\circ} \mathrm{C}$.

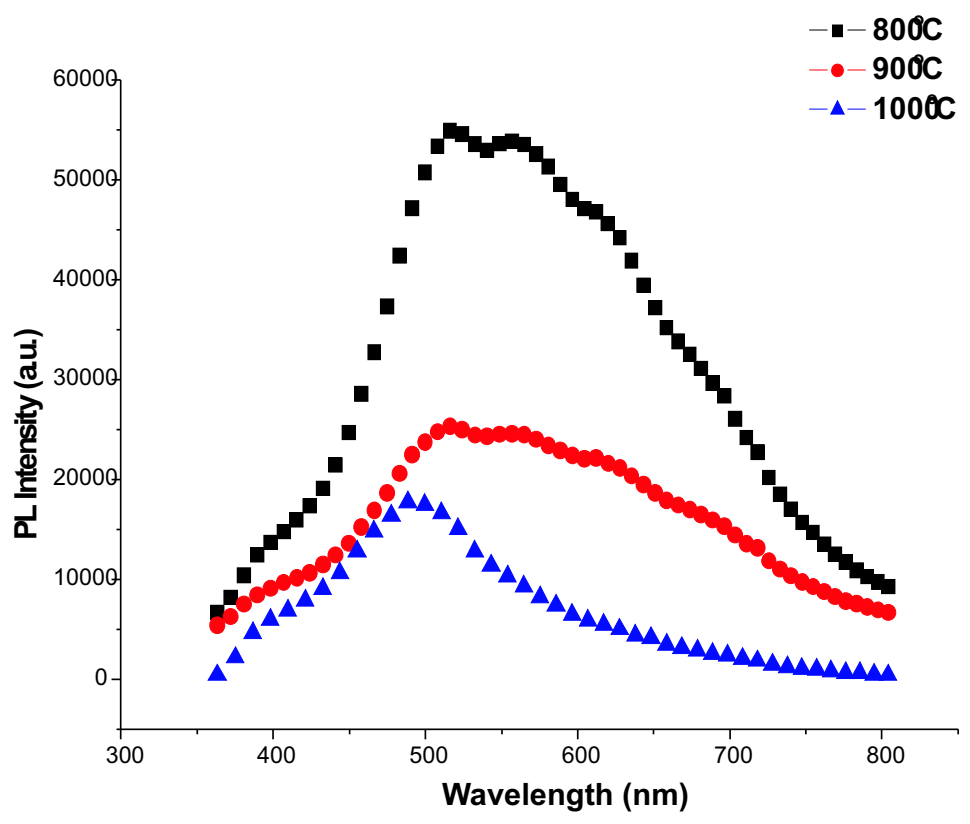

Fig. 4. Room temperature PL from $\mathrm{SiC}$ nanorods annealed at different temperatures.

The strong green-light emission band at about $520 \mathrm{~nm}$ is visible in the PL spectra after 1 hour thermal annealing at $800^{\circ} \mathrm{C}$. Further increase of annealing temperature gives the blue-shift of PL peak at $490 \mathrm{~nm}\left(1000^{\circ} \mathrm{C}\right.$ anneal). The observed PL intensity decreased with increase of temperature. In general, high-temperature annealing is expected to produce a complete recombination of point defects through diffusion of mobile oxygen in $\mathrm{SiO}_{2}$. It can quench defects, dissolve some luminescence centers and offer energy to produce new phase in the matrix of $\mathrm{SiO}_{2}$ [9]. Therefore, if the PL originate from defectrelated luminescence centers, the intensity should be reduced with increasing annealing temperature.

Two broad peaks of PL at $\sim 550$ and $610 \mathrm{~nm}$ have been seen at 800 and $900^{\circ} \mathrm{C}$ and completely vanished at $1000^{\circ} \mathrm{C}$ anneal. This PL is most probably due to oxygen related defects in amorphous $\mathrm{SiO}_{x}$ region. 
One another shoulder in PL spectra at about $380 \mathrm{~nm}$ in all different annealing temperatures is clearly observed. Based on stability of this blue-light emission band with annealing, we suggest that the behavios is associated with the formation of some $\mathrm{SiC} / \mathrm{SiO}{ }_{x}$ nanocables, where this structure emit stable violet-blue light at wavelengths of about $315 \mathrm{~nm}$ and 360-400 $\mathrm{nm}[10]$.

Our experimental observations, and in particular the observed blue-shift of the emission band with increasing annealing temperature could be better explained by $\mathrm{Si}_{y} \mathrm{C}_{1-y} \mathrm{O}_{x}$ complexes from nanorods with $\mathrm{SiC}$ core- $\mathrm{SiO}_{2}$ shell structure. More experimental work is necessary for a complete understanding of the origin of the blue-light emission band.

\section{CONCLUSION}

In conclusion, we observed room-temperature visible photoluminescence from 3C$\mathrm{SiC}$ nanorods grown by carbothermal reduction of silica xerogel containing carbon particles. Significant light emission was observed at room temperature after annealing at high temperature in ambient air. The peak position shifts from 520 to $490 \mathrm{~nm}$ for annealing cycles at high temperature $\left(800-1000^{\circ} \mathrm{C}\right)$. The structure of $\mathrm{SiC}$ nanorods should open the way to new intense blue-green light-emitting diodes.

\section{ACKNOWLEGMENTS}

The authors wish to thank N. X. Nghia, T. D Thanh, N. T. Ngan for their help in the measurements. This research is supported by the Local Research program of the Institute of Materials Science 2008.

\section{REFERENCES}

[1] L.T. Canham, Appl. Phys. Lett. 57 (1990)1046-1048.

[2] A. O. Konstantinov, A. Henry, C. I. Harris, and E. Janzen, Appl. Phys. Lett. 66 (1995) 2250-2252.

[3] V. Petrova-Koch, O. Sreseli, G. Polisski, D. Kovalev, T. Muschik, and F. Koch, Thin Solid Films 255 (1995) 107.

[4] Weiqiang Han, Shoushan Fan, Qunqing Li, Wenjie Liang, Binglin Gu, and Dapeng Yu, Chemical Physics Letters 265 (1997) 374-378.

[5] D. H. Feng, T. Q. Jia, X. X. Li, Z. Z. Xu, J. Chen, S. Z. Deng, Z. S. Wu, and N. S. Xu, Solid State Communications 128 (2003) 295-297.

[6] Zhang Yafei, Nishitani-Gamo Mikka, Xiao Changyong, J. Appl. Phys. 91 (9) (2002) 6066-6079.

[7] G. W. Meng, L. D. Zhang, C. M. Mo, Metallurgical and Materials Transactions 30A (1999) 213-219.

[8] H. T. Ha, L. Q. Huy, D. T. Cao, Advances in Natural Sciences 8 (3\&4) (2007) 217-222.

[9] J. Zhao, D. S. Mao, Z. X. Lin, B. Y. Jiang, Y. H. Yu, X. H. Liu, H. Z. Wang and G. Q. Yang, Appl. Phys. Lett. 73 (1998) 1838-1840.

[10] Xue-Min Liu et al., Nanotechnology 16 (2005) 2932-2935.

Received 27 September 2009. 